\title{
The Reporter System for GPCR Assay with the Fission Yeast Schizosaccharomyces pombe
}

\author{
Shintaro Sasuga and Toshiya Osada \\ Department of Life Science, Graduate School of Bioscience and Biotechnology, Tokyo Institute of Technology, B-2 4259 Nagatsuta-cho, \\ Midori-ku, Yokohama 226-8501, Japan \\ Correspondence should be addressed to Toshiya Osada; tosada@bio.titech.ac.jp
}

Received 31 October 2012; Accepted 11 December 2012

Academic Editors: J. R. Blazquez and M. De Angelis

Copyright (C) 2012 S. Sasuga and T. Osada. This is an open access article distributed under the Creative Commons Attribution License, which permits unrestricted use, distribution, and reproduction in any medium, provided the original work is properly cited.

G protein-coupled receptors (GPCRs) are associated with a great variety of biological activities. Yeasts are often utilized as a host for heterologous GPCR assay. We engineered the intense reporter plasmids for fission yeast to produce green fluorescent protein (GFP) through its endogenous GPCR pathway. As a control region of GFP expression on the reporter plasmid, we focused on seven endogenous genes specifically activated through the pathway. When upstream regions of these genes were used as an inducible promoter in combination with LPI terminator, the mam2 upstream region produced GFP most rapidly and intensely despite the high background. Subsequently, LPI terminator was replaced with the corresponding downstream regions. The SPBC4.01 downstream region enhanced the response with the low background. Furthermore, combining SPBC4.01 downstream region with the sxa2 upstream region, the signal to noise ratio was obviously better than those of other regions. We also evaluated the time- and dose-dependent GFP productions of the strains transformed with the reporter plasmids. Finally, we exhibited a model of simplified GPCR assay with the reporter plasmid by expressing endogenous GPCR under the control of the foreign promoter.

\section{Introduction}

In mammalians, G protein-coupled receptors (GPCRs) constitute the largest and most divergent protein families. GPCRs are activated by hormones, odorants, peptides, neurotransmitters, and so on [1-3]. Not surprisingly, it is often the case that GPCRs are associated with various diseases; GPCRs are one of the most potential drug targets, along with enzymes. However, it is difficult to reproduce appropriate and functional GPCR expression in heterologous cells due to the distinctive conformation and unknown mechanism of its trafficking and folding. Therefore, a large number of GPCRs still do not determine the corresponding ligands. Today, a wide variety of hosts and their transformants have been developed to resolve these problems [4-10].

Fission yeast, Schizosaccharomyces pombe, is a unicellular eukaryote and the best model organism especially in cell cycle. Fission yeast shares more similarities to mammals in terms of mRNA splicing, posttranslational modification, and so on than other yeasts including budding yeast, Saccharomyces cerevisiae [11]. Indeed, many genes of fission yeast can be complemented by the mammalian homologs, and many mammalian proteins are successfully expressed in fission yeast cells [12-17]. Although fission yeast has so many advantages in expressing heterologous protein, it is preferable not to select fission yeast in the GPCR study.

Fission yeast endogenously follows two alternative GPCR pathways. One is the nutrient (glucose) signaling pathway [18] and the other is the mating pathway. This mating pathway closely resembles the mitogen-activated protein kinase (MAPK) pathway in mammalian cells $[19,20]$. A fission yeast cell usually divides by mitosis in rich medium. However, exposed to nutrient starvation (particularly nitrogen starvation), the cell converts mitosis to meiosis by which the cell develops into robust spores with opposite mating type via pheromone communication for resistance to environmental stress $[20,21]$. One mating type, plus cell $(h+$ or $\mathrm{P}$ cell), secretes diffusible peptide pheromone, which 
is P-factor encoded by map2 gene. Another mating type, minus cell ( $h-$ or M cell), receives P-factor by the endogenous GPCR, which is Mam2 protein encoded by mam 2 gene $[22,23]$. The pheromone reception triggers sequential and synergistical activation of mating specific genes, which results in morphological changes for later conjugation to opposite mating type [23, 24].

In this study, we proposed the screening system with fission yeast through the endogenous mating pathway to find the ligand of a number of orphan GPCRs. As a reporter gene, the intense genes such as LacZ or luciferase are often utilized in GPCR assay with yeasts $[8-10,25]$, but we used green fluorescent protein (GFP) with a focus on easy and inexpensive detection in spite of a very weak signal compared to that of intense genes. In order to overcome this disadvantage, we constructed the tractable reporter plasmids.

\section{Materials and Methods}

2.1. Strains and Media. The strains used in this study are listed in Table 1. The fission yeast cells were grown in EMM (Edinburgh Minimal Medium, Sunrise Science Products, CA, USA) or EMM-N (EMM minus Nitrogen, Sunrise Science Products). Transformants were plated onto MMA (Minimal Medium Agar, Sunrise Science Products) or MMA supplemented with $1.25 \%$ leucine ( $120 \mu \mathrm{L} /$ plate).

Escherichia coli strain DH5 $\alpha$ was used for the subcloning of the plasmid preparation.

Peptide and oligonucleotide synthesis were performed by Operon Co. Ltd. (Tokyo, Japan). Each peptide was prepared as a stock solution of $1 \mathrm{mM}$ in Milli-Q water and stored at $-80^{\circ} \mathrm{C}$.

\subsection{Plasmid Constructions and Transformations}

2.2.1. Gene Disruption. The gene disruption was performed by standard homologous recombination method. The detailed construction of the plasmids for gene disruption was described previously [26]. Briefly, about $1000 \mathrm{bp}$ of $5^{\prime}$ and 3 ' flanking sequences of a target gene were used as the chromosomal integration regions. To delete the ura4 selection marker, the ura4 gene was sandwiched with about 200 bp of 3 flanking sequence of the target gene. For negative selection of the ura4-cells, the cells were plated onto the YES-FOA plates $(0.5 \%$ Yeast Extract, $3 \%$ glucose and SP Supplements, 2\% Bacto agar, 0.1\% 5-fluoroorotic acid). The resultant ura4-cells were available for the subsequent gene recombination.

2.2.2. Reporter Plasmids Based on PAL7. The reporter plasmids were engineered based on pAL7 which was a high copy plasmid for fission yeast [27]. The schematic illustration was described in Figure 1. The main fragment including the replication origin and selection marker was amplified from pAL7 using primers pAL7invforward and pAL7invreverse. The fragment was ligated with a series of a certain promoter, GFP, and Lipocortin I (LPI) terminator. To replace

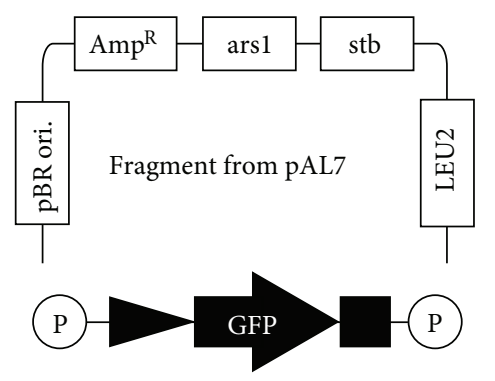

GFP fragment including promoter and terminator

(a)

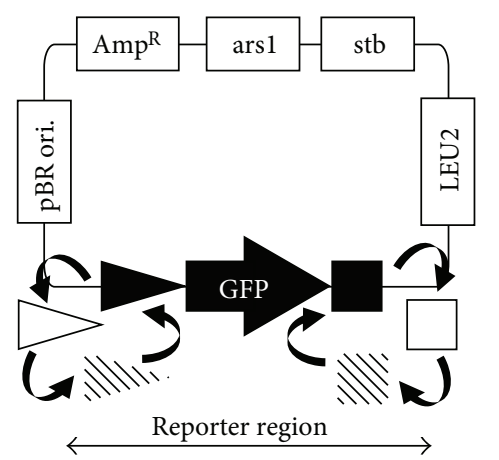

(b)

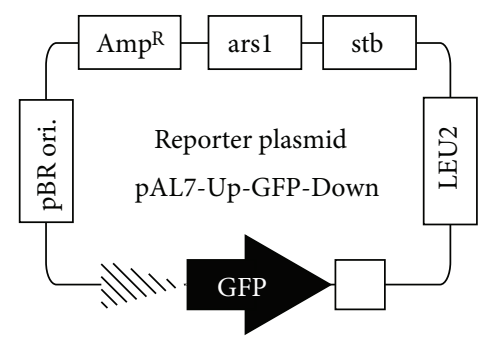

(c)

FIGURE 1: The schematic illustration of reporter plasmid construction. (a) Ligation of the fragment amplified from pAL7 and the phosphated fragment including a series of promoter, GFP (filled arrow) and LPI terminator (filled box). (b) Conversion of the promoter into any upstream regions (shaded and open triangles), and conversion of the LPI terminator into any downstream regions (shaded and open boxes). (c) Completion of converting upstream and downstream region. All reporter plasmids listed in Table 1 were constructed in this way.

the promoter region with each upstream region of the pheromone-dependent gene, inverse PCR was performed from the resultant plasmid using primers pAL7invreverse and GFPORFforward. To replace the LPI terminator, inverse PCR was performed using primers pAL7invforward and GFPORFreverse. Open reading frame (ORF) of GFP used in this study was amplified from a Monster Green Fluorescent Protein phMGFP Vector (Promega Japan, Tokyo, Japan). LPI terminator was amplified from a pSU1Z vector (Asahi Glass Co., Ltd, Tokyo, Japan). Upstream and downstream regions were amplified from a genomic DNA, and the primers were listed in Table 3. 
TABLE 1: Fission yeast strains used in this study.

\begin{tabular}{|c|c|}
\hline Strain & Genotype \\
\hline OSP210 & h-, leu1-32, ura4-D18, sxa2s \\
\hline OSP210-0 & h-, leu1-32, ura4-D18, sxa2A, pSU1Z, pAL7 \\
\hline OSP210-1 & h-, leu1-32, ura4-D18, sxa2A, pSU1Z, pAL7-Udhc1-GFP-LPI \\
\hline OSP210-2 & h-, leu1-32, ura4-D18, sxa2A, pSU1Z, pAL7-Umam2-GFP-LPI \\
\hline OSP210-3 & h-, leu1-32, ura4-D18, sxa2A, pSU1Z, pAL7-Umam3-GFP-LPI \\
\hline OSP210-4 & h-, leu1-32, ura4-D18, sxa2 $\Delta$, pSU1Z, pAL7-Urgs1-GFP-LPI \\
\hline OSP210-5 & h-, leu1-32, ura4-D18, sxa2A, pSU1Z, pAL7-USPBC4.01-GFP-LPI \\
\hline OSP210-6 & h-, leu1-32, ura4-D18, sxa2A, pSU1Z, pAL7-Uspk1-GFP-LPI \\
\hline OSP210-7 & h-, leu1-32, ura4-D18, sxa2A, pSU1Z, pAL7-Usxa2-GFP-LPI \\
\hline OSP210-8 & h-, leu1-32, ura4-D18, sxa2A, pSU1Z, pAL7-Udhc1-GFP-D dhc1 \\
\hline OSP210-9 & h-, leu1-32, ura4-D18, sxa2s, pSU1Z, pAL7-Umam2-GFP-Dmam2 \\
\hline OSP210-10 & h-, leu1-32, ura4-D18, sxa2A, pSU1Z, pAL7-Umam3-GFP-Dmam3 \\
\hline OSP210-11 & h-, leu1-32, ura4-D18, sxa2A, pSU1Z, pAL7-Urgs1-GFP-Drgs1 \\
\hline OSP210-12 & h-, leu1-32, ura4-D18, sxa2A, pSU1Z, pAL7-USPBC4.01-GFP-DSPBC4.01 \\
\hline OSP210-13 & h-, leu1-32, ura4-D18, sxa2A, pSU1Z, pAL7-Uspk1-GFP-Dspk1 \\
\hline OSP210-14 & h-, leu1-32, ura4-D18, sxa2A, pSU1Z, pAL7-Usxa2-GFP-Dsxa2 \\
\hline OSP210-15 & h-, leu1-32, ura4-D18, sxa2A, pSU1Z, pAL7-Umam2-GFP-DSPBC4.01 \\
\hline OSP210-16 & h-, leu1-32, ura4-D18, sxa2A, pSU1Z, pAL7-Umam3-GFP-DSPBC4.01 \\
\hline OSP210-17 & h-, leu1-32, ura4-D18, sxa2A, pSU1Z, pAL7-Usxa2-GFP-DSPBC4.01 \\
\hline OSP220 & h-, leu1-32, ura4-D18, sxa $2 \Delta$, cyr $1 \Delta$ \\
\hline OSP220-0 & $h-$, leu1-32, ura4-D18, sxa2 $\Delta$, cyr1 1 , pSU1Z, pAL7 \\
\hline OSP220-2 & h-, leu1-32, ura4-D18, sxa2 $\Delta$, cyr1 1 , pSU1Z, pAL7-Usxa2-GFP-DSPBC4.01 \\
\hline OSP220-17 & 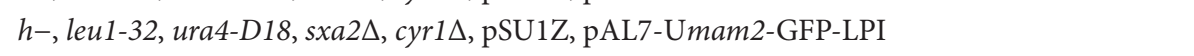 \\
\hline OSP230 & h-, leu1-32, ura4-D18, sxa2 $\Delta, \operatorname{mam} 2 \Delta$, \\
\hline OSP230-17 & h-, leu1-32, ura4-D18, sxa2 $\Delta$, mam2 2 , pSU1Z, pAL7-Usxa2-GFP-DSPBC4.01 \\
\hline OSP230-17n1 & 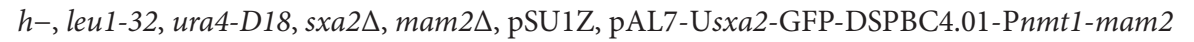 \\
\hline OSP230-17u1 & 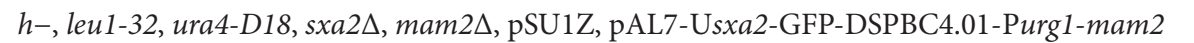 \\
\hline OSP230-17h1 & h-, leu1-32, ura4-D18, sxa2 $\Delta$, mam2 $\Delta$, pSU1Z, pAL7-Usxa2-GFP-DSPBC4.01-PhCMV-mam2 \\
\hline OSP230-17n2 & 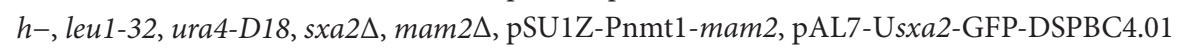 \\
\hline OSP230-17u2 & 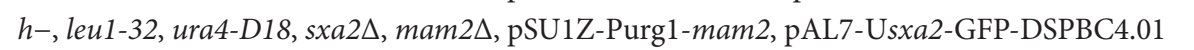 \\
\hline OSP230-17h2 & h-, leu1-32, ura4-D18, sxa2 $\Delta$, mam2 $\Delta$, pSU1Z-PhCMV-mam2, pAL7-Usxa2-GFP-DSPBC4.01 \\
\hline OSP230-2h2 & h-, leu1-32, ura4-D18, sxa2 $\Delta$, mam2 $\Delta$, pSU1Z-PhCMV-mam2, pAL7-Umam2-GFP-LPI \\
\hline
\end{tabular}

2.2.3. mam2 Gene Expression Plasmid. pSU1Z vector allows the expression of particular genes under the control of the hCMV promoter at the ura4 locus on the fission yeast chromosome. To express mam 2 gene under the control of other promoters, we replaced hCMV promoter with $n m t 1$ or urg1 promoter. The region of $n m t 1$ promoter was referred to pREP1 vector and that of $\operatorname{urg} 1$ was referred to the region reported by Watt et al. [28]. To repress the nmt1 promoter, more than $15 \mu \mathrm{M}$ of thiamine were added to the medium. To induce the $n m t 1$ promoter, the cells were incubated in fresh EMM without thiamine for 20 hours. During the preincubation, urg1 promoter was consistently repressed by the absence of uracil. On the contrary, urg1 promoter was constitutively activated during the assay by the nitrogen starvation.

All PCR products used for the plasmid construction were prepared using the KOD-plus-Neo (Toyobo, Osaka, Japan) in accordance with the supplier's instructions. All fragments without the replication origin of Escherichia coli were phosphorylated with T4 Polynucleotide Kinase (Toyobo) and the ligation reactions were performed with a LigationConvenience Kit (Nippon gene, Tokyo, Japan). The sequence of each plasmid was verified by the nucleotide sequence analysis.

2.2.4. Transformation. The fission yeast was transformed using a lithium acetate method [27, 29]. Transformed cells were plated onto MMA plates or MMA plates supplemented with leucine. The plates were incubated at $32^{\circ} \mathrm{C}$ for 2-3 days, and positive colonies were selected. To check for correct integration, PCR was performed on the extracted DNA using SapphireAmp Fast PCR Master Mix (Takara Bio Inc., Otsu, Japan). All the parental strains in this study lacked the function of both leu1+ and ura4+. Before assay, leu1-32 was complemented with LEU2 derived from pAL7 (or its derivatives) and ura4-D18 was complemented with ura4 gene derived from $\mathrm{PSU} 1 \mathrm{Z}$ vector (or its derivatives). 
TABLE 2: The reporter plasmids and the GFP production of those transformants.

\begin{tabular}{|c|c|c|c|c|c|c|c|c|}
\hline \multirow{2}{*}{ Plasmid name } & \multicolumn{3}{|c|}{ Reporter region of reporter plasmid } & \multirow{2}{*}{ Resultant strain } & \multicolumn{3}{|c|}{ Fluorescence intensity at } & \multirow{2}{*}{$\mathrm{SNR}^{\mathrm{c}}$} \\
\hline & upstream & reporter & downstream & & $0 \mathrm{~h}$ & $24 \mathrm{~h}(-)^{\mathrm{a}}$ & $24 \mathrm{~h}(+)^{\mathrm{b}}$ & \\
\hline pAL7-Udhc1-GFP-LPI & $d h c 1$ & GFP & LPI & OSP210-1 & $1.07( \pm 0.12)$ & $1.02( \pm 0.03)$ & $1.05( \pm 0.04)$ & 1.03 \\
\hline pAL7-Umam2-GFP-LPI & mam2 & GFP & LPI & OSP210-2 & $1.14( \pm 0.10)$ & $4.05( \pm 0.43)$ & $28.62( \pm 5.74)$ & 7.07 \\
\hline pAL7-Umam3-GFP-LPI & $\operatorname{mam3}$ & GFP & LPI & OSP210-3 & $1.05( \pm 0.10)$ & $1.02( \pm 0.10)$ & $7.66( \pm 2.21)$ & 7.51 \\
\hline pAL7-Urgs1-GFP-LPI & $\operatorname{rgs} 1$ & GFP & LPI & OSP210-4 & $1.52( \pm 0.14)$ & $1.88( \pm 0.23)$ & $4.12( \pm 0.98)$ & 2.19 \\
\hline $\begin{array}{l}\text { pAL7-USPBC4.01-GFP- } \\
\text { LPI }\end{array}$ & SPBC4.01 & GFP & LPI & OSP210-5 & $1.06( \pm 0.13)$ & $1.09( \pm 0.06)$ & $3.75( \pm 2.64)$ & 3.44 \\
\hline pAL7-Uspk1-GFP-LPI & $\operatorname{spk} 1$ & GFP & LPI & OSP210-6 & $1.15( \pm 0.08)$ & $1.58( \pm 0.18)$ & $3.71( \pm 0.74)$ & 2.35 \\
\hline pAL7-Usxa2-GFP-LPI & sxa2 & GFP & LPI & OSP210-7 & $1.05( \pm 0.09)$ & $1.05( \pm 0.09)$ & $9.82( \pm 2.09)$ & 9.35 \\
\hline pAL7-Udhc1-GFP-Ddhc1 & $d h c 1$ & GFP & $d h c 1$ & OSP210-8 & $1.07( \pm 0.12)$ & $1.02( \pm 0.03)$ & $1.06( \pm 0.05)$ & 1.04 \\
\hline $\begin{array}{l}\text { pAL7-Umam2-GFP- } \\
\text { Dmam2 }\end{array}$ & $\operatorname{mam} 2$ & GFP & $\operatorname{mam} 2$ & OSP210-9 & $1.04( \pm 0.13)$ & $1.15( \pm 0.20)$ & $6.46( \pm 1.06)$ & 5.62 \\
\hline $\begin{array}{l}\text { pAL7-Umam3-GFP- } \\
\text { Dmam3 }\end{array}$ & mam3 & GFP & mam3 & OSP210-10 & $1.05( \pm 0.13)$ & $0.99( \pm 0.11)$ & $4.02( \pm 1.68)$ & 4.06 \\
\hline pAL7-Urgs1-GFP-Drgs1 & $\operatorname{rgs} 1$ & GFP & rgsl & OSP210-11 & $1.44( \pm 0.09)$ & $2.36( \pm 0.90)$ & $7.96( \pm 3.27)$ & 3.37 \\
\hline $\begin{array}{l}\text { pAL7-USPBC4.01-GFP- } \\
\text { DSPBC } 4.01\end{array}$ & SPBC4.01 & GFP & SPBC4.01 & OSP210-12 & $1.05( \pm 0.08)$ & $1.03( \pm 0.31)$ & $7.84( \pm 1.85)$ & 7.61 \\
\hline pAL7-Uspk1-GFP-Dspk1 & $s p k 1$ & GFP & $\operatorname{spk} 1$ & OSP210-13 & $1.17( \pm 0.15)$ & $1.25( \pm 0.03)$ & $4.64( \pm 1.31)$ & 3.71 \\
\hline pAL7-Usxa2-GFP-Dsxa2 & sxa2 & GFP & sxa2 & OSP210-14 & $1.12( \pm 0.17)$ & $1.03( \pm 0.06)$ & $8.43( \pm 2.91)$ & 8.18 \\
\hline $\begin{array}{l}\text { pAL7-Umam2-GFP- } \\
\text { DSPBC4.01 }\end{array}$ & mam2 & GFP & SPBC4.01 & OSP210-15 & $0.99( \pm 0.02)$ & $1.21( \pm 0.15)$ & $6.99( \pm 3.19)$ & 5.78 \\
\hline $\begin{array}{l}\text { pAL7-Umam3-GFP- } \\
\text { DSPBC4.01 }\end{array}$ & $\operatorname{mam} 3$ & GFP & SPBC4.01 & OSP210-16 & $1.03( \pm 0.03)$ & $0.99( \pm 0.08)$ & $6.40( \pm 2.96)$ & 6.46 \\
\hline $\begin{array}{l}\text { pAL7-Usxa2-GFP- } \\
\text { DSPBC4.01 }\end{array}$ & $s x a 2$ & GFP & SPBC4.01 & OSP210-17 & $0.99( \pm 0.04)$ & $1.06( \pm 0.05)$ & $15.54( \pm 3.09)$ & 14.66 \\
\hline
\end{tabular}

Each value of fluorescence intensity was mean $( \pm \mathrm{SD})$ from more than three independent experiments. ${ }^{\mathrm{a}}(-)$ : incubation without $\mathrm{P}-$ factor. ${ }^{\mathrm{b}}(+)$ : incubation with P-factor. ${ }^{c}$ SNR: signal to noise ratio, SNR was obtained by dividing the fluorescence intensity at $24 \mathrm{~h}(+)$ by that at $24 \mathrm{~h}(-)$.

TABLE 3: Primer information.

\begin{tabular}{lccll}
\hline Primer name & Target gene & Region & Forward $\left(5^{\prime} \rightarrow 3^{\prime}\right)$ & Reverse $\left(5^{\prime} \rightarrow 3^{\prime}\right)$ \\
\hline pAL7inv & & & GAGCAAAAGGCCAGCAAAAG & AACCGTATTACCGCCTTTGA \\
GFPORF & & & ATGGGCGTGATCAAGCCCG & TTAGCCGGCCTGGCGGGGT \\
dhclup & SPAC1093.06c/dhc1 & -1044 & AAGCACGCGCTCTAATTCAT & GGTGTCAAGAAAACTTGACCG \\
dhcldw & & +958 & AACTTGAAACTATTTGTTGTTACTA & GAATCTGAGGTTGATGTTGAA \\
mam2up & SPAC11H11.04/mam 2 & -1068 & CATCGGGATTGCATTGAGAGT & AATGTCAGAGGGAGCAAGAACA \\
mam2dw & & +1010 & CTTACGCCTGAATGTATCTTT & ACTCAAAGCCATAACTGTGC \\
mam3up & SPAP11E10.02c/mam3 & -1041 & TTTTAGAAAGTGTCTATTGTACC & GACGAATTATGGGAAGATCAAG \\
mam3dw & & +997 & ATAAAGTTAATGTTTTATATTTATTTTACA ACTGAGAATGTCGTCTGTCC \\
rgslup & SPAC22F3.12c/rgs1 & -1118 & GGCAGGTGTAAGAAGCGTTG & CCAAAGCTGATTCTTACTTTTACGA \\
rgsldw & & +944 & TGCATAGAAAACAATCGTGT & CGAAAGAATCCTGCTGTTAC \\
SPBC4.01up & SPBC4.01 & -985 & CCCATCTGGGTGAAAGAGTG & CCATTCTTAAACCGTAATTTTAAATTG \\
SPBC4.01dw & & +992 & ACAAACATAAATAAGATTTTGTAAAC & AATTATTGCTGTCGCCGAAC \\
spklup & SPAC31G5.09c/spk1 & -1040 & GGACGCCAAGGGAAATTTAT & TAGACTACAAATTGAAAAACTTGAAAG \\
spkldw & & +958 & AAAGCTTCAACTAGAATTCTCCT & CAACCGATGACGGTATTTAT \\
sxa2up & SPAC1296.03c/sxa2 & -1363 & AGATTATGGGGTAGTGGGTTC & GCATTGAAAAGAGAGACAATGA \\
sxa2dw & & +945 & AAGTTTAATATCGGAAAATTTAA & CGGAAGTTAGGCTTGTGTGC
\end{tabular}

${ }^{\mathrm{a}}$ Region represents how distant from ATG or stop codon of its target gene is ORF, 


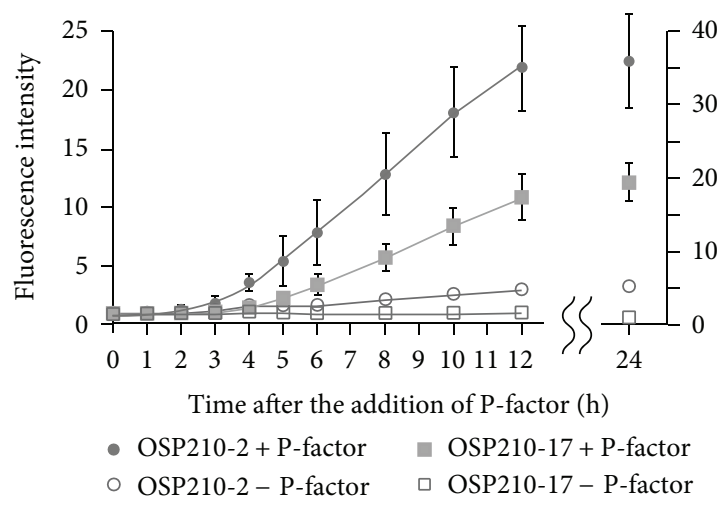

(a)

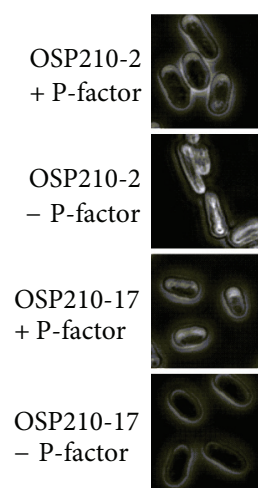

0
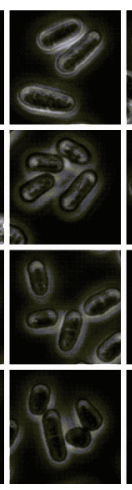

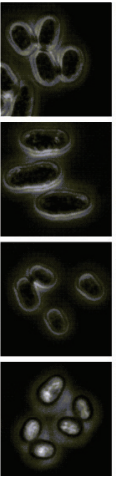

2

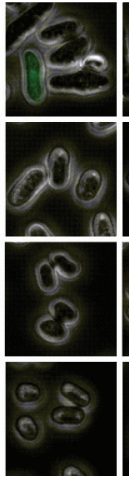

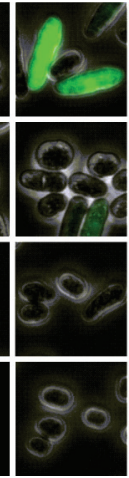

4

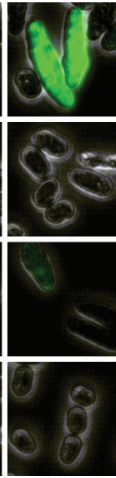

5

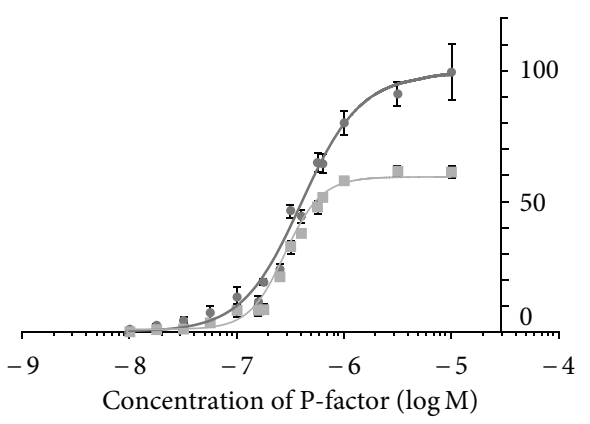

- OSP210-2 EC50 $=0.41 \mu \mathrm{M}( \pm 0.11)$

- OSP210-17 EC50 $=0.28 \mu \mathrm{M}( \pm 0.075)$

(c)

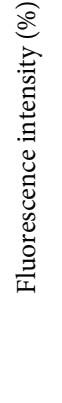

Time after the addition of P-factor (h)

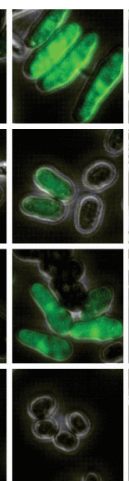

6

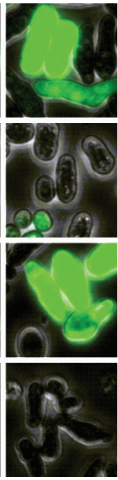

8

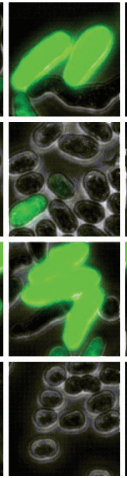

10

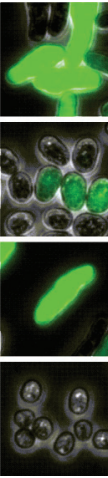

12

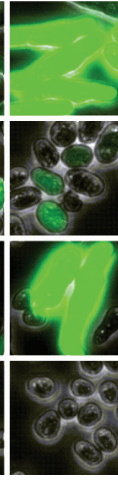

24

(b)

Figure 2: Time- and dose-dependent response to P-factor with the reporter plasmids. (a) Time-dependent response to P-factor with either pAL7-Umam2-GFP-LPI or pAL7-Usxa2-GFP-DSPBC4.01. The cells were exposed to 1 or $0 \mu \mathrm{M}$ of P-factor and were taken every hour (0-6 h), two hours (6-12 h) or twelve hours (12-24 h). Filled circle depicts OSP210-2 (sxa2 , pAL7-Umam2-GFP-LPI) +P-factor, open circle depicts OSP210-2 -P-factor, filled square depicts OSP210-17 (sxa2s, pAL7-Usxa2-GFP-DSPBC4.01) +P-factor and open square depicts OSP210-17 -P-factor. The values were the means of triplicate determinations from a typical experiment. The error bars represent \pm standard error. (b) Aliquots of culture medium $(2 \mu \mathrm{L})$ were mounted on slides and visualized by a fluorescence microscope. After the addition of P-factor, the morphology was gradually changed and the production of GFP increased. Scale bar $=10 \mu \mathrm{m},(\mathrm{c})$ dose-dependent response. The cells were exposed to the various concentrations of P-factor and were incubated for 24 hours after the addition of P-factor. Filled circle depicts OSP210-2

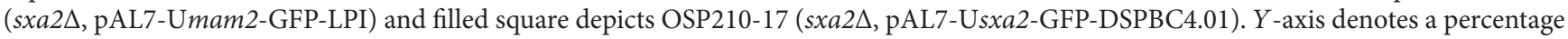
of the maximum response. The values were the means of triplicate determinations from a typical experiment.

\subsection{Assay}

2.3.1. Time-Dependent Assay. The cells were grown in EMM at $32^{\circ} \mathrm{C}$ for $24-36$ hours and were inoculated into $5 \mathrm{~mL}$ of the fresh EMM. Then the cells were grown at $30^{\circ} \mathrm{C}$ for 20 hours and harvested. After washing twice with sterile water, the cells were transferred to assay medium to give an initial optical density of 1.5 at $600 \mathrm{~nm}$. Immediately, P-factors were added at a final concentration of 1 or $0 \mu \mathrm{M}$. The cells in $500 \mu \mathrm{L}$ were taken every hour (0-6 h), two hours (6-12 h), or twelve hours (12-24h). Aliquots were resuspended in $500 \mu \mathrm{L}$ of Milli-Q water after being washed once. Fluorescence intensity of GFP produced in the cells was measured by a Hitachi F-2700 Fluorescence Spectrophotometer (Hitachi, Tokyo Japan). The relative fluorescence intensity was averaged and calculated as the ratio of the sample to the control strain harboring pAL7 instead of the reporter plasmid (OSP210-0 or OSP220-0). The images were taken on a Zeiss Axiovert 200M Inverted Microscope with the AxioCam MRm charge-coupled camera controlled by Axiovision. Assays were performed using independent transformants.

2.3.2. Dose-Dependent Assay. After preincubation, the cells were transferred to EMM-N to give an initial optical density of 1.5 at $600 \mathrm{~nm}$. The cells exposed to each concentration of P-factor were incubated at $30^{\circ} \mathrm{C}$ for 24 hours, and the fluorescence intensity was measured. Normalized data were fit to the equation: $E=E_{\max } /\left(1+\exp \left[\gamma *\left(\ln \left[\mathrm{EC}_{50}\right]-\ln [x]\right)\right]\right)$. $E$ represents the current response at each concentration 


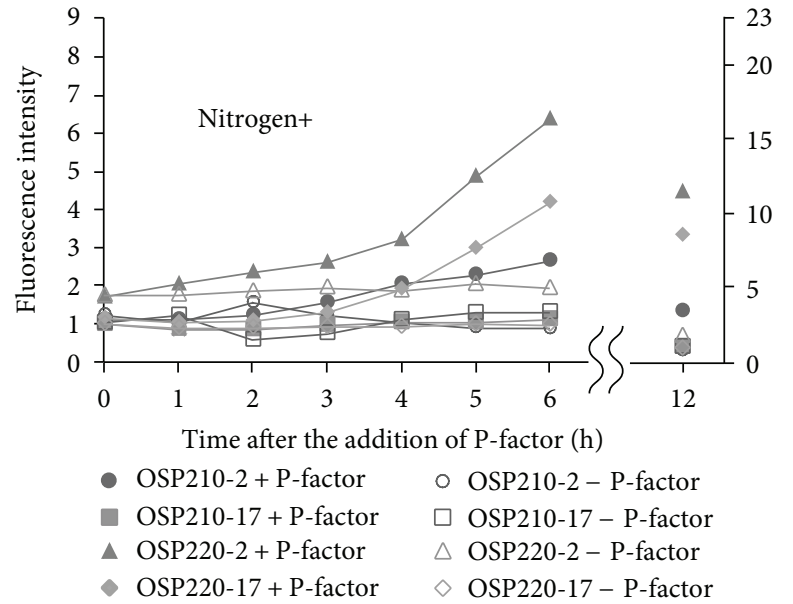

(a)

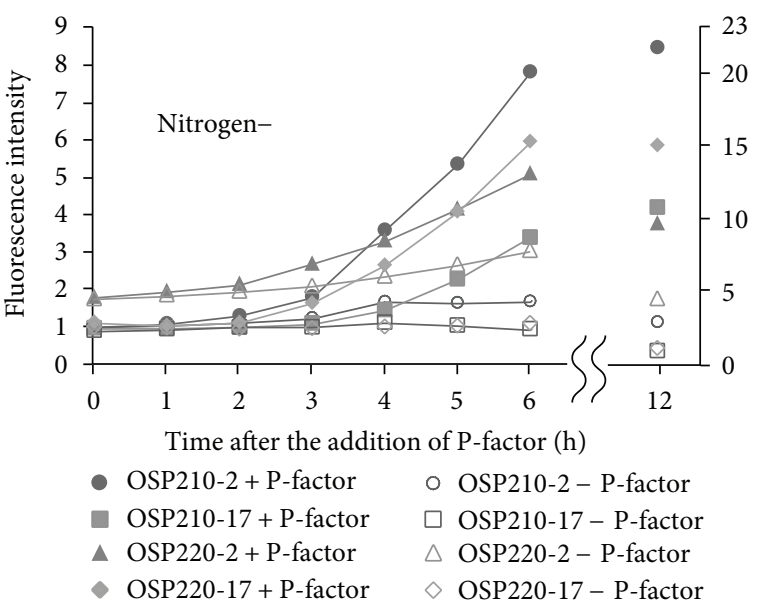

(b)

FIGURE 3: Comparison between cyrl $1 \Delta$ and $c y r 1+$ strains harboring the reporter plasmid. The cells were exposed to $1 \mu \mathrm{M}$ of P-factor in the presence of nitrogen (a) and the absence of nitrogen (b) and were taken every hour $(0-6 \mathrm{~h})$ or six hours (6-12 h). Filled circle depicts OSP210-2 (sxa2s, cyr1+, pAL7-Umam2-GFP-LPI) +P-factor, open circle depicts OSP210-2 -P-factor, filled square depicts OSP210-17 (sxa2, , cyr1+, pAL7-Usxa2-GFP-DSPBC4.01) +P-factor, open square depicts OSP210-17 -P-factor, filled triangle depicts OSP220-2 (sxa2 cyr1 $\Delta$, pAL7-Umam2-GFP-LPI) +P-factor, open triangle depicts OSP220-2 -P-factor, filled diamond shape depicts OSP220-17 (sxa2 $\Delta$, cyr1 $\Delta$, pAL7-Usxa2-GFP-DSPBC4.01) +P-factor, and open diamond shape depicts OSP220-17 -P-factor. The values were the means of triplicate determinations from a typical experiment.

of P-factor, $x . E_{\max }$ is the maximal response. $\mathrm{EC}_{50}$ is the concentration of $\mathrm{P}$-factor yielding a half maximal response. $\gamma$ is the Hill coefficient.

\section{Results}

3.1. Tractable Reporter Plasmid Developed from pAL7. To prepare the transformants for reporter assay, we constructed the new reporter plasmids with both tractability and sensitivity. The reporter plasmids made those transformants produce green fluorescent protein (GFP) through the Mam2-P-factor signal transduction pathway (mating pathway). To determine the most appropriate pheromone-dependent reporter region on the reporter plasmid, we focused on the 7 genes, which were previously reported to have been sharply activated by the addition of P-factor [24, 30]. The upstream regions of those genes were used as an inducible promoter for GFP. As the downstream region of GFP, we employed LPI terminator, which correctly worked as a gene terminator in the fission yeast cell. Each of the resultant plasmids (listed in Table 2) was transformed into the sxa2s strain, OSP210 ( $h-$, leu132 , ura4-D18, sxa2 $\Delta$ ). The reason why sxa2 gene was deleted was because Sxa2 protein was the specific peptidase of $\mathrm{P}$ factor. The response to the 1 or $0 \mu \mathrm{M}$ of $\mathrm{P}$-factor under nitrogen starvation was shown in Table 2. All upstream regions other than the $d h c 1$ upstream region expressed GFP. The mam 2 upstream region responded much more intensely than others. Nevertheless, the signal to noise ratio (SNR) of mam 3 and sxa2 upstream regions was better than that of the mam 2 upstream region. Next, we determined whether some downstream regions were more suitable for 3 ' UTR of GFP than the LPI terminator since it was reported that $3^{\prime}$ UTR of mRNA regulated its stability and had an effect on the expression level [31]. LPI terminator in the reporter region of each plasmid was replaced with the downstream region corresponding to its upstream region to reproduce the native genomic context. The combination of $d h c 1$ regions did not respond, suggesting that the important region for transcription might locate on ORF or the outside of the regions used in this study. The spkl downstream region decreased the background under the absence of P-factor. The mam 2 and mam 3 downstream regions obviously decreased the response to P-factor, while that of sxa2 showed little difference from LPI terminator. The SPBC4.01 and rgs 1 downstream regions raised the response dramatically, but it was clear that the rgs1 downstream region had raised the expression level without relying on P-factor. In an effort to prepare the appropriate reporter region, the mam2, mam3, and sxa2 upstream regionS presumably including the intense pheromone-dependent upstream activation sequence were combined with SPBC4.01 downstream region. As we had expected, the combination of the sxa2 upstream and SPBC4.01 downstream regions had raised the response with little increase of background. Thereby, the best SNR was obtained with this combination. We circumstantially investigated the two reporter plasmids; one is pAL7-Umam2GFP-LPI including the most intense reporter region and the other is pAL7-Usxa2-GFP-DSPBC4.01 whose reporter region exhibited the best $\mathrm{SNR}$.

We explored the time-dependent GFP production of the strains harboring pAL7-Umam2-GFP-LPI (OSP210-2) or pAL7-Usxa2-GFP-DSPBC4.01 (OSP210-17). The strains were exposed to 1 or $0 \mu \mathrm{M}$ of $\mathrm{P}$-factor under nitrogen starvation (Figure 2(a)). The strain OSP210-2 exhibited the 
mam2 gene located on reporter plasmid

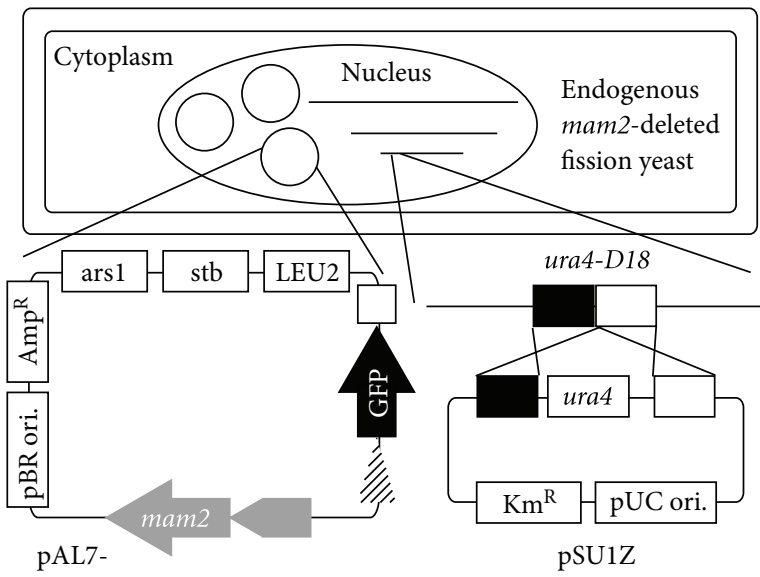

Usxa2-GFP-DSPBC4.01-

promoter-mam2

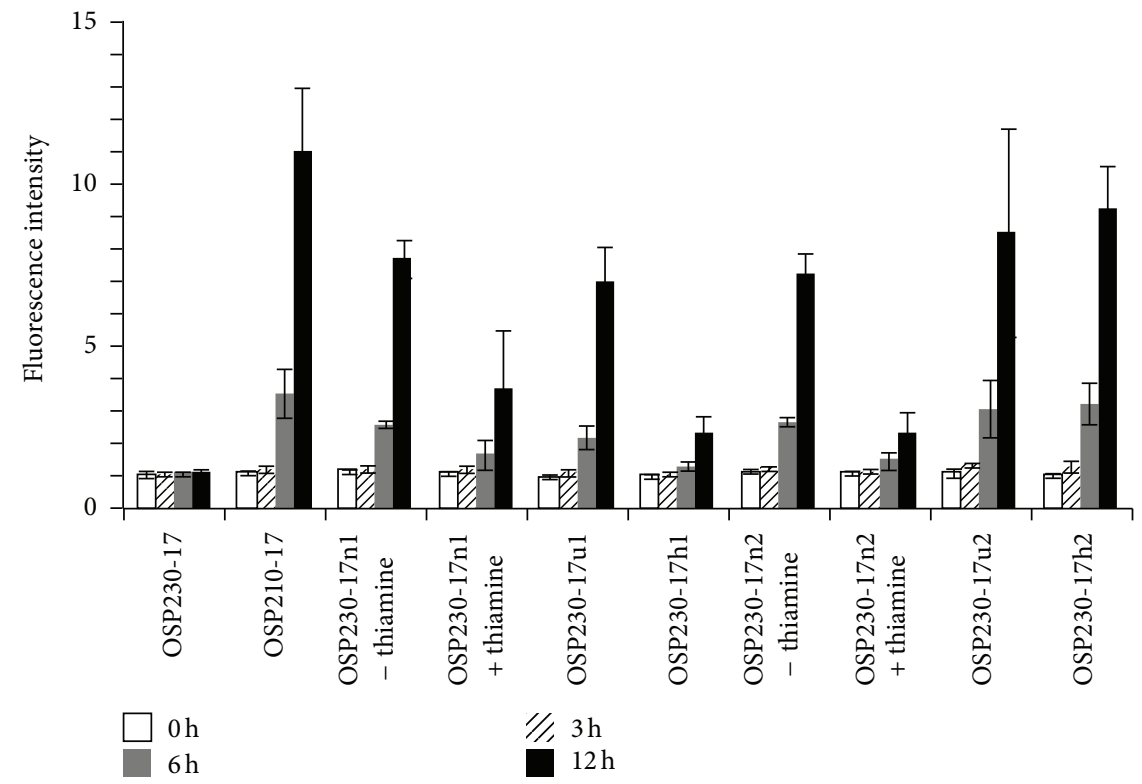

(b)

(a)

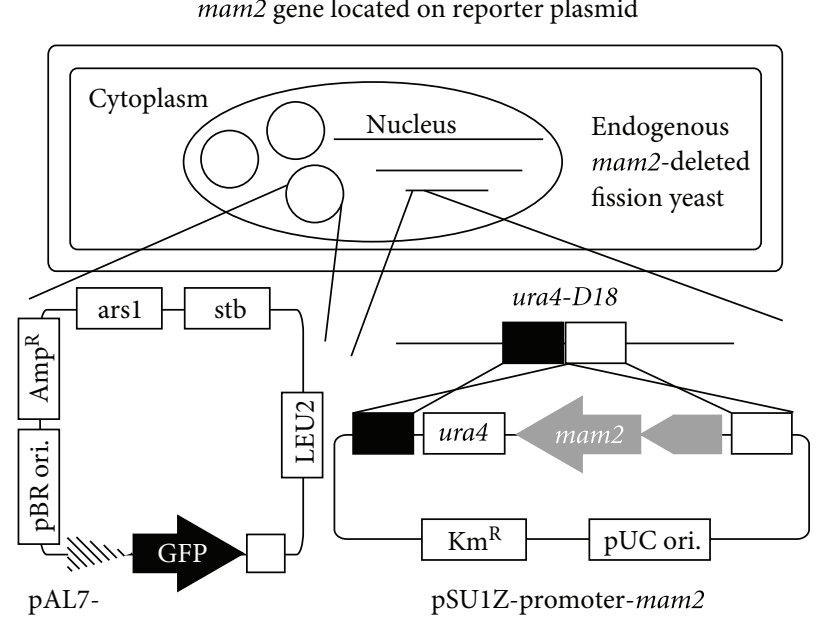

Usxa2-GFP-DSPBC4.01
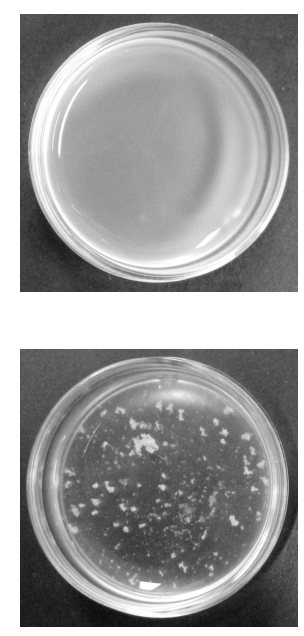

(c)

FIGURE 4: Ectopic mam2 expression in mam2 $2 \Delta$ strain. (a) The schematic strategy of ectopic mam 2 expression in endogenous mam $2 \Delta$ strain. Left, mam 2 gene (gray arrow) was driven on reporter plasmid. To complement ura4 gene, empty pSU1Z vector was introduced into ura4 locus on chromosome. Right, mam 2 gene on pSU1Z vector was introduced into the ura4 locus. The gray pentagon depicted the promoter, which was nmt1 promoter, urg1 promoter or hCMV promoter. The two plasmids (reporter and receptor) were transformed at the same time. (b) The mam 2 gene was expressed under the control of $n m t 1$ promoter, urg1 promoter or hCMV promoter on chromosome or the reporter plasmid. OSP210-17 was used as a positive control. OSP230-17 was used as a negative control and did not express mam2 gene under the control of any promoter. The cells were exposed to $1 \mu \mathrm{M}$ of P-factor and were incubated for $0 \mathrm{~h}$ (open box), $3 \mathrm{~h}$ (shaded box), $6 \mathrm{~h}$ (gray box), or $12 \mathrm{~h}$ (filled box) after the addition of P-factor. The strains including the $n m t 1$ promoter were assayed with 0 (on) or 15 (off) $\mu \mathrm{M}$ of thiamine. The urg1 promoter was constitutively activated under the nitrogen starvation. The values were the means of triplicate determinations from a typical experiment. The error bars represent \pm standard error. (c) Upper, the preculture medium of the strain OSP230-17 h2 expressing mam2 gene under the control of chromosomal hCMV promoter with pAL7-Usxa2-GFP-DSPBC4.01. Lower, the preculture medium of the strain OSP230-2 h2 expressing mam2 gene under the control of chromosomal hCMV promoter with pAL7-Umam2-GFP-LPI.

response with not only the intensity but also the rapidity, which enabled it to discriminate the positive reaction within $3 \mathrm{~h}$ after the addition of P-factor. However, the cells had produced measurable GFP protein without the addition of $\mathrm{P}$ factor. On the contrary, pAL7-Usxa2-GFP-DSPBC4.01 had caused the cells to produce little GFP protein in the absence of P-factor. The maximum value was relatively high, and the positive signal could be discriminated within $5 \mathrm{~h}$ after the addition of P-factor. These results corresponded to the observation with the fluorescent microscope (Figure 2(b)). In both 
strains, the luminous cells began to appear at the time when the GFP signal was detected by the fluorescent spectrometer. And the elongation of the cell body to form shmoos was also observed, which was the typical response induced by the reception of P-factor [23]. Curiously, the strain OSP2102 had begun to elongate about two hours earlier than the strain OSP210-17. We also explored the dose-dependent GFP production (Figure 2(c)). The response formed sigmoid curve clearly indicated that the Mam2-P-factor interaction was quantitatively measurable by these strains. Their EC50 values did not show a significant difference between the strains. It was suggested that the efficiency of the subsequent signal transduction pathway had to remain hardly affected by increasing the copy number of plasmids.

3.2. The cyr1s Strain with Reporter Plasmid. The adenylyl cyclase encoded by cyr1 gene is often deleted from the assay in the mating pathway. The $c y r 1 \Delta$ strain exhibits constitutive starvation regardless of the existence of nitrogen and carbon [32]. Being ready to receive the ligands at any time has an advantage in the mating pathway of the assay system, so we examined the effect of cyr1-deletion with reporter plasmids. The cells were exposed to 1 or $0 \mu \mathrm{M}$ of P-factor under the presence or absence of nitrogen, and the timedependent responses were measured (Figure 3). Under the presence of nitrogen, the cyr1 1 strain harboring pAL7Umam2-GFP-LPI (OSP220-2) responded most intensely at $12 \mathrm{~h}$. Compared to the strain without P-factor, the difference in GFP production began to appear at $3 \mathrm{~h}$ and was completely distinguishable at $4 \mathrm{~h}$ and beyond. However, these strains had already exhibited high background at $0 \mathrm{~h}$. On the other hand, the cyr1 $\Delta$ strain harboring pAL7-Usxa2-GFPDSPBC4.01 (OSP220-17) became distinguishable at $4 \mathrm{~h}$. In addition, the strain without P-factor did not produce GFP protein at all. Unsurprisingly, the cyr1+ strain harboring pAL7-Usxa2-GFP-DSPBC4.01 (OSP210-17) with or without P-factor did not show the response in the presence of nitrogen. Interestingly, the cyr1+ strain harboring pAL7Umam2-GFP-LPI (OSP210-2) could respond to P-factor by $12 \mathrm{~h}$ having passed even under the presence of nitrogen. Under the absence of nitrogen, the cyr1s strain OSP2202 was with high background and began to produce GFP at about $3 \mathrm{~h}$ as is the case in the presence of nitrogen. However, this strain did not raise the response as we had expected. The cyr $1 \Delta$ strain OSP220-17 became distinguishable about one hour earlier than cyr1+ strain OSP210-17, and the intensity of the response was also increased. The cyr1-deletion was quite effective in the strain OSP220-17 regardless of the existence of the nitrogen.

\subsection{The Ectopic mam 2 Expression in the Strain Harboring} Reporter Plasmid. As a model for heterologous GPCR assay with the reporter plasmid, the mam 2 gene was ectopically expressed under the control of other promoters in the endogenous mam $2 \Delta$ strain, OSP230 (h-, leu1-32, ura4-D18, $s x a 2 \Delta, \operatorname{mam} 2 \Delta)$. Three promoters were used to express the mam 2 gene; the first is no message in thiamine 1 (nmt1) promoter, which is the most common inducible promoter and exhibits the strongest expression in the fission yeast $[33,34]$; the second is uracil regulatable 1 (urg1) promoter, which is an inducible promoter and expressed moderately. While urg1 promoter is repressed by the removal of uracil from the medium, it was maximally induced by either the addition of the uracil or the removal of the nitrogen [28]; the third is human cytomegalovirus (hCMV) promoter which is the strong promoter activated constitutively [35]. The mam2 gene was driven on either of the chromosomal integration vectors for fission yeast, pSU1Z vector (or its derivatives) or the reporter plasmid (Figure 4(a)). The transformation to introduce the receptor and the reporter was performed at the same time. When the parental strain OSP230 was cotransformed by $150 \mathrm{ng}$ of the reporter plasmid and $150 \mathrm{ng}$ of the linearized integration vector, $37(\mathrm{SD} \pm 14)$ colonies appeared. Exposed to $1 \mu \mathrm{M}$ of P-factor, the response could be adequately detected in 5 mam 2 expression patterns out of 6 , which fell slightly below that in the native expression pattern (Figure 4(b)). Perhaps too much accumulation of Mam2 protein might hinder the GFP production in the strain OSP230$17 \mathrm{~h} 1$ whose mam2 was constitutively expressed under the control of hCMV promoter on the high copy plasmid. On the other hand, the GFP production was not inhibited by the constitutive chromosomal expression whose mam 2 expression was smaller than episomal expression. The induced $n m t 1$ promoter shows little difference between the episomal and chromosomal expression. Under this experimental condition in which the cells were pre-incubated for $20 \mathrm{~h}$, the mam 2 gene was strongly expressed by induced $n m t 1$ promoter for $2-5 \mathrm{~h}$ after the intracellular thiamine was completely carried out of the cell body. Regulating the pre-incubation time might improve the response. In spite of the addition of thiamine, the $n m t 1$ promoter was not completely repressed. This result coincided with the previous data [28]. The urgl promoter did not show a significant difference between the episomal and chromosomal expression. In both strains, it was very easy to operate $u r g 1$ promoter since that was automatically repressed and induced under this experimental condition. Although we followed the same procedure with pAL7-Umam2-GFP-LPI as we had with pAL7-Usxa2-GFP-DSPBC4.01, the assay had gone wrong. The reason why we could not assay was that the cells formed aggregates that did not respond to P-factor at all during the preculture (Figure 4(c)).

\section{Discussion}

4.1. New Reporter System. The reporter system constructed in this study was considerably tractable. These reporter plasmids were easily transformed with high efficiency even at the same time as the chromosomal integration vector was introduced. In addition, the plasmid is so flexible that it is easy to reconstruct; for example, the selection marker could be changed depending on the genotype of laboratory stock strains. Moreover, as enough GFP for detection was produced in this assay system, the reporter gene did not have to be an intense one such as lac $Z$ or luciferase, which required the substrate degradation at the detection for sensitive readout. As a reporter region of the plasmid, we concluded that a 
combination of sxa2 upstream region and the SPBC4.01 downstream region was the most suitable due to the best SNR. The cells responding to P-factor began to appear at $5 \mathrm{~h}$ and became obviously luminous at $6 \mathrm{~h}$, while few luminous cells appeared for $24 \mathrm{~h}$ in the absence of P-factor. The combination of mam2 upstream region and LPI terminator responded most rapidly and intensely of all, and began to respond at $3 \mathrm{~h}$ and became absolutely distinguishable at $4 \mathrm{~h}$. However, we were not able to recommend using the reporter region for two reasons: firstly because of the excessively high background (many luminous cells appeared within $8 \mathrm{~h}$ and SNR was not so good compared to others), and secondly because nonspecific aggregation was readily formed.

4.2. The Combination of the Reporter Plasmid and cyr1Deletion. In the combination of pAL7-Usxa2-GFPDSPBC4.01, the cyr1-deletion had both positive and negative aspects. The positive aspects were that the assay medium was not limited and that the cells responded a few hours earlier. The negative aspects were that the cyr $1 \Delta$ strains became more difficult to deal with; for example, it took a longer time to divide (maximum doubling time of OSP210$17 \rightarrow$ OSP220-17: $3.20 \mathrm{~h} \rightarrow 4.76 \mathrm{~h}$ at $30^{\circ} \mathrm{C}$ in EMM) and the transformation efficiency became significantly lower (about one hundredth). In addition to those demerits, what was worse was what occurred in the cyr1 $\Delta$ strain harboring pAL7-Umam2-GFP-LPI. Under nitrogen starvation, the cyrl $1 \Delta$ strain responded less intensely than the $c y r 1+$ strain. One explanation could be that there was a difference in the optimal pre-incubation time to maximally respond to Pfactor between the strain OSP220-2 and other strains. It was implied that in order to retain pAL7-Umam2-GFP-LPI, the intracellular condition had to be slightly affected (described below).

4.3. Ectopic mam2 Expression. As a model for the heterologous GPCRs, we expressed mam2 gene under the control of three kinds of promoters in the mam $2 \Delta$ strain. It was fundamentally convenient for the associated experiments to express the receptor gene on the reporter plasmid, although the huge receptor expression could cause problems in the response. The expression by the $n m t 1$ and $\operatorname{urg} 1$ promoter on the high copy plasmid had little impact on the reception of Pfactor, but the reduction of response was seen in the strain whose mam 2 gene was constitutively expressed by hCMV promoter on the high copy plasmid. It was suggested that too much Mam2 production presumably caused the unfolded protein response, which had a harmful effect on the cell [36]. Thus, it would be indispensable to repress the heterologous GPCR expression during mitosis. In fact, $n m t 1$ promoter could reproduce the response well in spite of demonstrating stronger expression than hCMV promoter. When the assay with urg1 promoter was performed, the operations were very easy because the cells were automatically repressed and induced in this system. However, note that the induction of urg1 promoter can depend on the intracellular condition [28], so the cyr $1 \Delta$ strain might be unable to repress the expression of $u r g 1$ promoter as well as the cyrl+ strain.
4.4. Intracellular Effect of pAL7-Umam2-GFP-LPI. The Cyr1 protein is required through the nutrient pathway to perceive not nitrogen but rather a carbon resource [37]. In fact, the cyrl-deletion makes the cell unable to perceive the carbon resource. However, carbon starvation does not result in the autophagy for meiosis, which is induced by nitrogen starvation [38]. The reason why the cyrl-deletion (carbon starvation mimic) affects the mating pathway is presumably because it facilitates expression of the ste11 gene which commonly plays a key role in several intracellular signal transduction pathways including not only mating pathway but also nutrition signaling and stress signaling pathways [30, 37]. In this study, there was some circumstantial evidence suggesting that such the ste11-induction was seen in the cyr1+ strain harboring pAL7-Umam2-GFP-LPI (OSP210$2)$. The strain OSP210-2 could respond to P-factor even under the existence of nitrogen (Figure 3). Furthermore, the morphological change made progress about two hours earlier than that of the strain OSP210-17 (Figure 2(b)). The promoter and/or activating regions must be related to the GFP production, but the regions are unlikely to have an effect on the morphological change. It was suggested that DNA and/or RNA derived from pAL7-Umam2-GFP-LPI made stel1 gene more likely to be induced as is often the case with stress response and nutrient starvation.

\section{Acknowledgments}

The authors would like to thank Dr. Hideki Tohda (Asahi Glass Co., LTD, Kanagawa, Japan) for his technical assistance and for kindly providing plasmids (pAL7 and pSU1) and yeast strain ARC010 (h-, leu1-32, ura4-D18), from which all strains in this study derived. This work was supported by a Grant-in-Aid for Creative Scientific Research (no. 19GS0418) from the Japan Society for the Promotion of Science and by the Foundation of Advanced Technology Institute.

\section{References}

[1] T. Iiri, Z. Farfel, and H. R. Bourne, "G-protein diseases furnish a model for the turn-on switch," Nature, vol. 394, no. 6688, pp. 35-38, 1998.

[2] L. Buck and R. Axel, "A novel multigene family may encode odorant receptors: a molecular basis for odor recognition," Cell, vol. 65 , no. 1, pp. 175-187, 1991.

[3] J. S. Gutkind, "The pathways connecting G protein-coupled receptors to the nucleus through divergent mitogen-activated protein kinase cascades," The Journal of Biological Chemistry, vol. 273, no. 4, pp. 1839-1842, 1998.

[4] V. Sarramegna, F. Talmont, P. Demange, and A. Milon, "Heterologous expression of G-protein-coupled receptors: comparison of expression systems from the standpoint of largescale production and purification," Cellular and Molecular Life Sciences, vol. 60, no. 8, pp. 1529-1546, 2003.

[5] K. Yoshikawa and K. Touhara, "Myr-Ric-8A enhances G $\alpha 15$ mediated $\mathrm{Ca} 2+$ response of vertebrate olfactory receptors," Chemical Senses, vol. 34, no. 1, pp. 15-23, 2009.

[6] Z. Cheng, D. Garvin, A. Paguio, P. Stecha, K. Wood, and F. Fan, "Luciferase reporter assay system for deciphering GPCR pathways," Current Chemical Genomics, vol. 4, pp. 84-91, 2010. 
[7] J. Kempf, L. A. Snook, J.-L. Vonesch, T. E. S. Dahms, F. Pattus, and D. Massotte, "Expression of the human $\mu$ opioid receptor in a stable Sf9 cell line," Journal of Biotechnology, vol. 95, no. 2, pp. 181-187, 2002.

[8] S. A. Chasse and H. G. Dohlman, "Identification of yeast pheromone pathway modulators by high-throughput agonist response profiling of a yeast gene knockout strain collection," Methods in Enzymology, vol. 389, pp. 399-409, 2004.

[9] J. Minic, M.-A. Persuy, E. Godel et al., "Functional expression of olfactory receptors in yeast and development of a bioassay for odorant screening," FEBS Journal, vol. 272, no. 2, pp. 524-537, 2005.

[10] G. Ladds, K. Davis, E. W. Hillhouse, and J. Davey, "Modified yeast cells to investigate the coupling of $G$ protein-coupled receptors to specific G proteins," Molecular Microbiology, vol. 47, no. 3, pp. 781-792, 2003.

[11] Y. Giga-Hama and H. Kumagai, "Expression system for foreign genes using the fission yeast Schizosaccharomyces pombe," Biotechnology and Applied Biochemistry, vol. 30, no. 3, pp. 235-244, 1999.

[12] M. G. Lee and P. Nurse, "Complementation used to clone a human homologue of the fission yeast cell cycle control gene cdc2," Nature, vol. 327, no. 6117, pp. 31-35, 1987.

[13] H. Mukaiyama, H. Tohda, and K. Takegawa, "Overexpression of protein disulfide isomerases enhances secretion of recombinant human transferrin in Schizosaccharomyces pombe," Applied Microbiology and Biotechnology, vol. 86, no. 4, pp. 1135-1143, 2010.

[14] K. Takegawa, H. Tohda, M. Sasaki et al., "Production of heterologous proteins using the fission-yeast (Schizosaccharomyces pombe) expression system," Biotechnology and Applied Biochemistry, vol. 53, no. 4, pp. 227-235, 2009.

[15] A. Idiris, K. Bi, H. Tohda, H. Kumagai, and Y. Giga-Hama, "Construction of a protease-deficient strain set for the fission yeast Schizosaccharomyces pombe, useful for effective production of protease-sensitive heterologous proteins," Yeast, vol. 23, no. 2, pp. 83-99, 2006.

[16] P. Sander, S. Grünewald, H. Reiländer, and H. Michel, "Expression of the human D2S dopamine receptor in the yeasts Saccharomyces cerevisiae and Schizosaccharomyces pombe: a comparative study," FEBS Letters, vol. 344, no. 1, pp. 41-46, 1994.

[17] S. Arkinstall, M. Edgerton, M. Payton, and K. Maundrell, "Coexpression of the neurokinin NK2 receptor and G-protein components in the fission yeast Schizosaccharomyces pombe," FEBS Letters, vol. 375, no. 3, pp. 183-187, 1995.

[18] R. M. Welton and C. S. Hoffman, "Glucose monitoring in fission yeast via the gpa $2 \mathrm{G} \alpha$, the git5 $\mathrm{G} \beta$ and the git 3 putative glucose receptor," Genetics, vol. 156, no. 2, pp. 513-521, 2000.

[19] O. Nielsen and J. Davey, "Pheromone communication in the fission yeast Schizosaccharomyces pombe," Seminars in Cell and Developmental Biology, vol. 6, no. 2, pp. 95-104, 1995.

[20] Y. Harigaya and M. Yamamoto, "Molecular mechanisms underlying the mitosis-meiosis decision," Chromosome Research, vol. 15, no. 5, pp. 523-537, 2007.

[21] S. S. Y. Su, Y. Tanaka, I. Samejima, K. Tanaka, and M. Yanagida, "A nitrogen starvation-induced dormant G0 state in fission yeast: the establishment from uncommitted G1 state and its delay for return to proliferation," Journal of Cell Science, vol. 109, no. 6, pp. 1347-1357, 1996.

[22] K. Kitamura and C. Shimoda, "The Schizosaccharomyces pombe mam 2 gene encodes a putative pheromone receptor which has a significant homology with the Saccharomyces cerevisiae Ste2 protein," The EMBO Journal, vol. 10, no. 12, pp. 3743-3751, 1991.

[23] Y. Imai and M. Yamamoto, "The fission yeast mating pheromone P-factor: its molecular structure, gene structure, and ability to induce gene expression and G1 arrest in the mating partner," Genes \& Development, vol. 8, no. 3, pp. 328-338, 1994.

[24] Y. Xue-Franzén, S. Kjærulff, C. Holmberg, A. Wright, and O. Nielsen, "Genomewide identification of pheromone-targeted transcription in fission yeast," BMC Genomics, vol. 7, article 303, 2006.

[25] C. S. Hoffman and F. Winston, "Glucose repression of transcription of the Schizosaccharomyces pombe fbp1 gene occurs by a cAMP signaling pathway," Genes \& Development, vol. 5, no. 4, pp. 561-571, 1991.

[26] S. Sasuga, R. Abe, O. Nikaido et al., "Interaction between pheromone and its receptor of the fission yeast Schizosaccharomyces pombe examined by a force spectroscopy study," Journal of Biomedicine and Biotechnology, vol. 2012, Article ID 804793, 7 pages, 2012.

[27] K. Okazaki, N. Okazaki, K. Kume, S. Jinno, K. Tanaka, and H. Okayama, "High-frequency transformation method and library transducing vectors for cloning mammalian cDNAs by transcomplementation of Schizosaccharomyces pombe," Nucleic Acids Research, vol. 18, no. 22, pp. 6485-6489, 1990.

[28] S. Watt, J. Mata, L. López-Maury, S. Marguerat, G. Burns, and J. Bähler, "urg1: A uracil-regulatable promoter system for fission yeast with short induction and repression times," PLoS One, vol. 3, no. 1, Article ID e1428, 2008.

[29] T. Morita and K. Takegawa, "A simple and efficient procedure for transformation of Schizosaccharomyces pombe," Yeast, vol. 21, no. 8, pp. 613-617, 2004.

[30] J. Mata and J. Bähler, "Global roles of Ste11p, cell type, and pheromone in the control of gene expression during early sexual differentiation in fission yeast," Proceedings of the National Academy of Sciences of the United States of America, vol. 103, no. 42, pp. 15517-15522, 2006.

[31] L. Malquori, L. Carsetti, and G. Ruberti, "The 3 UTR of the human CTLA4 mRNA can regulate mRNA stability and translational efficiency," Biochimica et Biophysica Acta, vol. 1779, no. 1, pp. 60-65, 2008.

[32] T. Maeda, N. Mochizuki, and M. Yamamoto, "Adenylyl cyclase is dispensable for vegetative cell growth in the fission yeast Schizosaccharomyces pombe," Proceedings of the National Academy of Sciences of the United States of America, vol. 87, no. 20, pp. 7814-7818, 1990.

[33] G. Basi, E. Schmid, and K. Maundrell, “TATA box mutations in the Schizosaccharomyces pombe nmt1 promoter affect transcription efficiency but not the transcription start point or thiamine repressibility," Gene, vol. 123, no. 1, pp. 131-136, 1993.

[34] A. Matsuyama, A. Shirai, and M. Yoshida, "A series of promoters for constitutive expression of heterologous genes in fission yeast," Yeast, vol. 25, no. 5, pp. 371-376, 2008.

[35] H. Tohda, H. Okada, Y. Giga-Hama, H. Okayama, and H. Kumagai, "A copy-number-controlled expression vector for the fission yeast Schizosaccharomyces pombe," Gene, vol. 150, no. 2, pp. 275-280, 1994.

[36] K. Ikesugi, R. Yamamoto, M. L. Mulhern, and T. Shinohara, "Role of the unfolded protein response (UPR) in cataract formation," Experimental Eye Research, vol. 83, no. 3, pp. 508-516, 2006. 
[37] M. Yamamoto, "The selective elimination of messenger RNA underlies the mitosis-meiosis switch in fission yeast," Proceedings of the Japan Academy B, vol. 86, no. 8, pp. 788-797, 2010.

[38] H. Mukaiyama, M. Nakase, T. Nakamura, Y. Kakinuma, and K. Takegawa, "Autophagy in the fission yeast Schizosaccharomyces pombe," FEBS Letters, vol. 584, no. 7, pp. 1327-1334, 2010. 

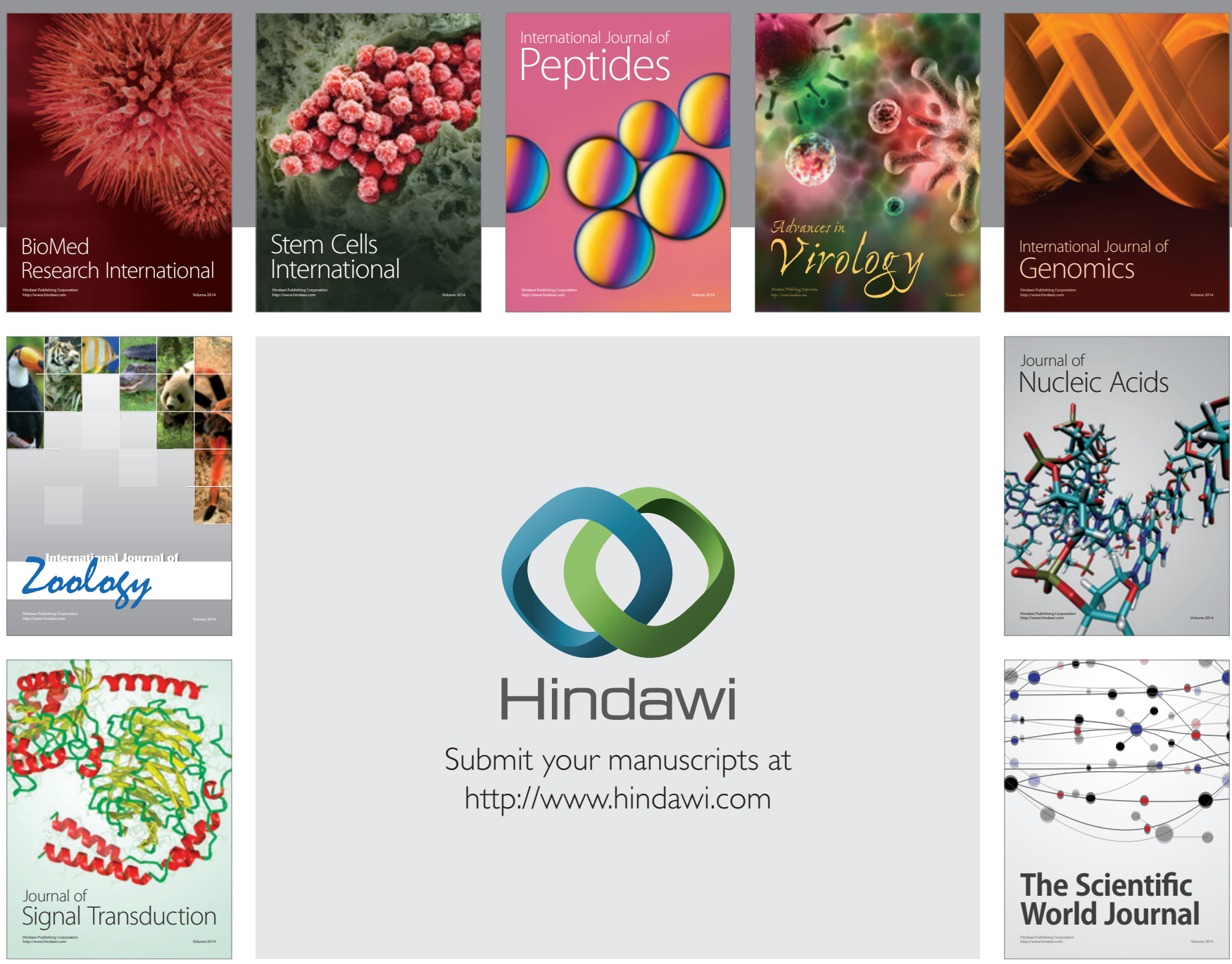

Submit your manuscripts at

http://www.hindawi.com
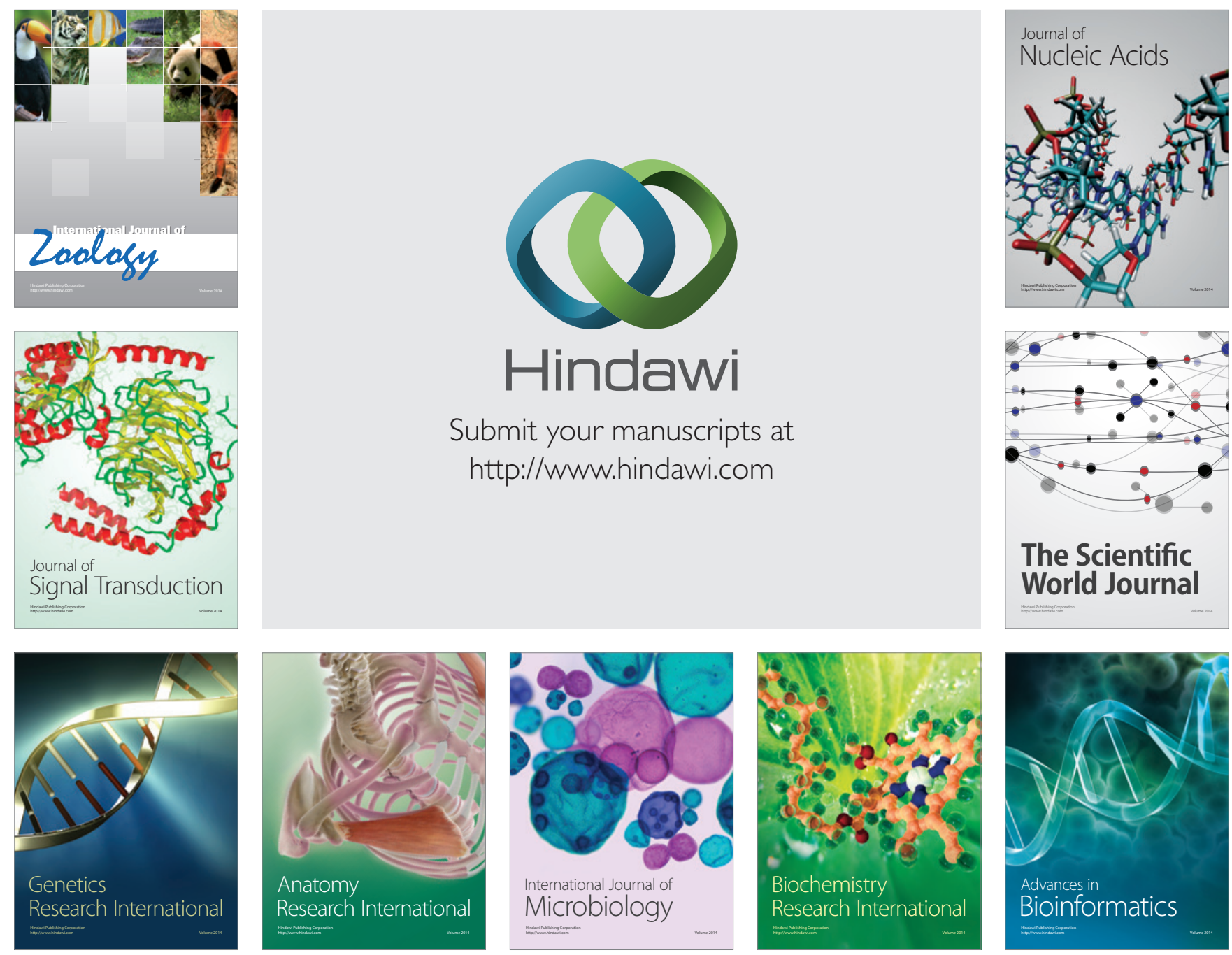

The Scientific World Journal
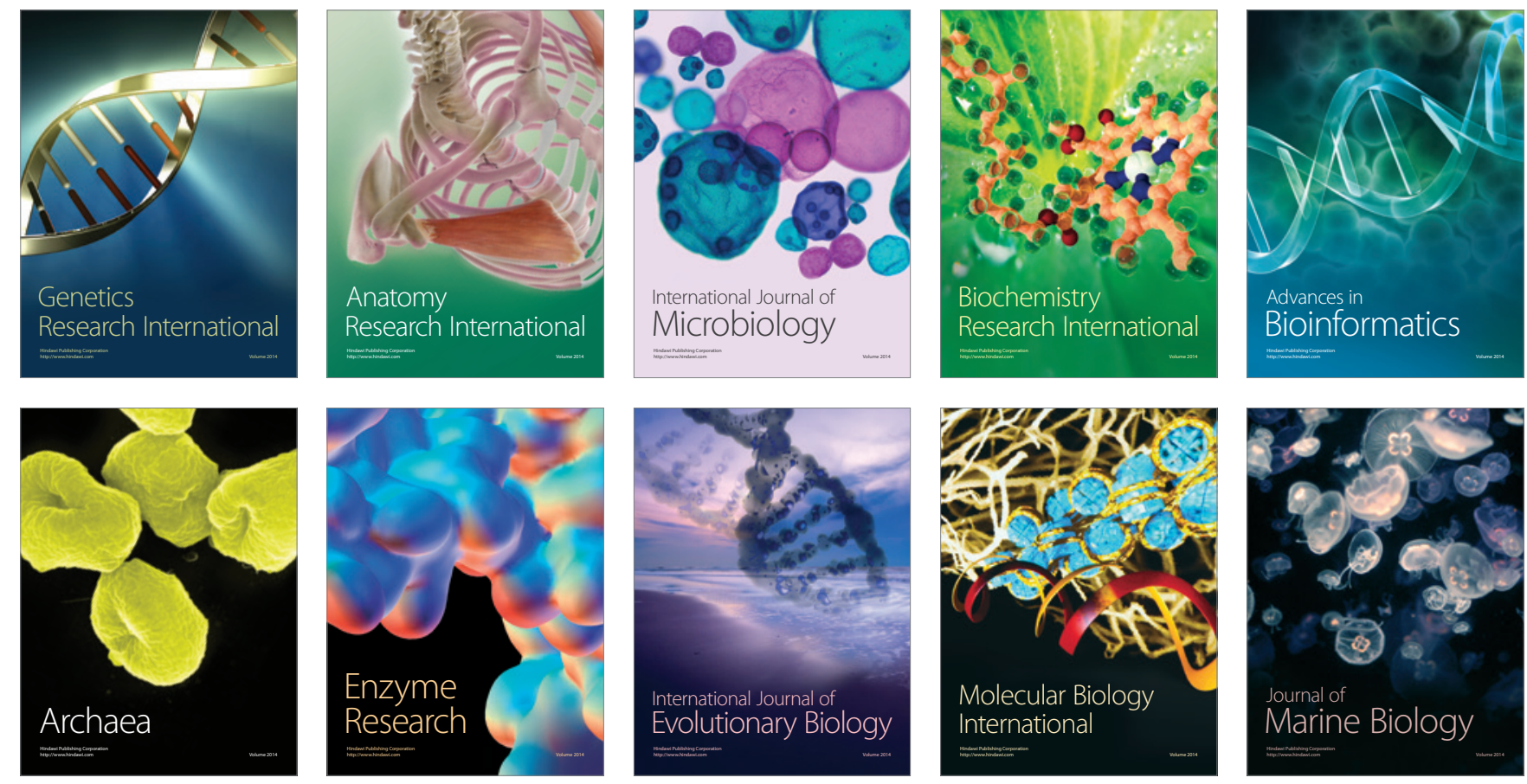